\title{
Lead borate glasses and synergistic impact of lanthanum oxide additive: optical and nuclear radiation shielding behaviors
}

\author{
A. S. Abouhaswa ${ }^{1,2} \cdot$ Hesham M. H. Zakaly ${ }^{1,3}$ (D) Shams A. M. Issa ${ }^{3,4} \cdot$ Mariia Pyshkina $^{1,5} \cdot$ R. El-Mallawany $^{2}$. \\ Mostafa Y. A. Mostafa ${ }^{1,6}$
}

Received: 6 May 2020 / Accepted: 13 July 2020 / Published online: 27 July 2020

(c) Springer Science+Business Media, LLC, part of Springer Nature 2020

\begin{abstract}
Composition of $(50-x) \mathrm{B}_{2} \mathrm{O}_{3}-30 \mathrm{PbO}-20 \mathrm{ZnO}-x \mathrm{La}_{2} \mathrm{O}_{3}(x=0,1.5,3,4.5$, and 6$) \mathrm{wt} \%$ glass system were synthesized using quench melt technique and simulated for their nuclear radiation shielding properties. Moreover, UV-visible absorption spectrum among 190-1100 nm and the glass optical parameters were measured. The optical energy gap $\left(E_{\mathrm{g}}\right)$, the singleoscillator energy $\left(E_{\mathrm{o}}\right)$, the dispersion energy parameter $\left(E_{\mathrm{d}}\right)$, refractive index $(n)$, and refractive dispersion index (no) were estimated. The obtained results indicated that $\left(E_{\mathrm{g}}\right)$ was decreased with increasing $\mathrm{La}_{2} \mathrm{O}_{3}$ content, but the refractive index $(n)$ was increased. The addition of $\mathrm{La}_{2} \mathrm{O}_{3}$ to glass network could provide preferable shielding features. The chosen amount of $\mathrm{La}$ and another metal oxide has been added to the glass. Shielding parameters such as half-value layer (HVL), mean free path (MFP), mass attenuation coefficient (MAC), and exposure rate in the photon energy range 15-300 keV have been simulated by MicroShield software. These results illustrate that the La5 glass sample has the best radiation shielding properties, among other investigated glasses. This type of glass sample can utilize for the construction of the monitoring screening windows in radiation areas, plats, or screening windows in X-ray diagnostic and for the walls of CT-scanner rooms.
\end{abstract}

\section{Introduction}

Glass as radiation shielding is utilized at many facilities presenting radiation therapy and treatment such as nonstinging, LX Premium radiation shielding glass, high-performance radiation screening Movable LX Protective Portable

A. S. Abouhaswa

aliabohaswa@hotmail.com

Hesham M. H. Zakaly

h.m.zakaly@azhar.edu.eg

Ural Federal University, Yekaterinburg, Russia 620002

2 Physics Department, Menoufia University, Shebin El Koom 32511, Egypt

3 Physics Department, Faculty of Science, Al-Azhar University, Assuit 71524, Egypt

4 Physics Department, Faculty of Science, University of Tabuk, Tabuk, Saudi Arabia

5 Institute of Industrial Ecology UB RAS, Ekaterinburg, Russia

6 Department of Physics, Faculty of Science, Minia University, El-Minia, Egypt
Screens, and for applications in PET facilities GR Premium gamma radiation shielding glass $[1,2]$.

The improvement of research in the field of medicine has led to the manifestation of an assortment of medical imaging with different technologies using magnetic fields, electromagnetic waves, and radiation, besides the new methods and techniques for diagnosis and therapy or treatment that utilize radiation in control health and life protecting $[3,4]$. The significance and furthering the progress of medical radiation protection by developing the glass as radiation shielding for use in the diagnosis and therapy of disease thereby protect healthcare personal and medical researchers from exposure to electromagnetic waves and radiation while they care for patients. The use of glass should give more safety with fast and accurate protection. Photons Interaction with matter is significant in radiation biology and radiation medicine. Besides, double functions of a glass of being transparent to the visible light and absorption of gamma rays or neutrons have wide importance. Therefore, providing radiation shielding properties for observers or fitter are essential. Also, glass shielding property investigations are a motivating option for radioactive waste products storage for a long period [5-7]. Because weak dispersion and high refractive index of lanthanum oxide are employed to special optical glasses such as 
infrared-absorbing, telescope lenses and camera, materials of glass which contain $\mathrm{La}_{2} \mathrm{O}_{3}$ in their glass network will be transparent and colorless [8]. Lanthanum element is very proper for usage in radiation shielding application because of its advantageous characteristics such as high density and atomic number. Lanthanum oxide plays as the network modifier in borate glasses, which raises absorption peak sharpness and reduces the absorption peaks broadness [9].

The shielding properties of glass materials are developing for transparent windows in various radiation applications where seeing a radiation-equipped zone is required. Improvement of the shielding properties in glass materials supplies the best means of shielding in X-ray scanning and diagnostics systems. Attenuation is the base principle in gamma and X-ray shielding $[10,11]$. Due to the broad range composition, high homogeneity, and transparency of glass materials, they have considered promising in radiation protection. Many applications have been used in the energy with a range from 15 to $300 \mathrm{keV}$ such as the dental clinics, radiation protection spectacles, research laboratories, radiotherapy X-ray rooms [12].

In this work, a computational investigation has been performed to determine lanthanum glass attenuation properties, exposure rates, and required gamma shield thickness with a range of gamma energies from 15 to $300 \mathrm{keV}$.

\section{Experimental technique}

\subsection{Sample preparation and measurements}

The solid-state conventional process was used to prepare five glass samples with $(50-x) \mathrm{B}_{2} \mathrm{O}_{3}-30 \mathrm{PbO}-20 \mathrm{ZnO}-x \mathrm{La}_{2} \mathrm{O}_{3}$ compositions and different doping ratios $(x=0,1.5,3,4.5$, and $6 \mathrm{wt} \%$ (Table 1). The samples were labeled La1 $(x=0)$, $\mathrm{La} 2(x=1.5), \mathrm{La} 3(x=3), \mathrm{La} 4(x=4.5)$, and La5 $(x=6)$. Pure boron oxide $\left(\mathrm{B}_{2} \mathrm{O}_{3}\right)$, lead oxide $(\mathrm{PbO})$, zinc oxide $(\mathrm{ZnO})$, and lanthanum oxide $\left(\mathrm{La}_{2} \mathrm{O}_{3}\right)$ were mixed very finely and then pre-heated at $300{ }^{\circ} \mathrm{C}$ for $60 \mathrm{~min}$ to get the required homogeneity of the synthesized glasses. Produced mixtures were melted in a porcelain crucible at a temperature of $1100-1400{ }^{\circ} \mathrm{C}$ for $30 \mathrm{~min}$. The molten samples were cast in a stainless steel mold so that the glass samples assumed the shape of a disc. The melting temperature was raised with increasing lanthanum oxide until it reached to $1400{ }^{\circ} \mathrm{C}$ with $x=6$. After quenching, the glass samples were directly moved into a muffle furnace operating at $300{ }^{\circ} \mathrm{C}$ for annealing.

To study the structure of the samples, powder X-ray diffraction analysis has been used at room temperature (Bruker, AXS D8 Advance, Germany, CuK $\alpha$ radiation). Using Archimedes' principle, the densities of the samples were determined employing a digital balance and toluene $(\rho=0.86 \mathrm{~g} /$ $\mathrm{cm}^{3}$ ) as an involvement liquid at room temperature. Table 1 presents the chemical composition, molar volume, and density of the fabricated glasses. For optical measurements, a JASCO UV-Vis-NIR model V-570 spectrophotometer was used on the polished glass discs (Fig. 1). The glass samples discs were polished very carefully with diameter $1 \mathrm{~cm}$.

\subsection{Computational work}

MicroShield is a computer modelling code. The primary purpose of MicroShield is to estimate photon fluence and exposure rates from 16 geometries that accommodate offset dose points and as many as ten standard shields plus source self-shielding and cylinder cladding. MicroShield uses the point kernel technique to determine the photon fluence rate.

The numerical integration performed by MicroShield is the Gaussian quadrature with a Gauss-Legendre method for determining abscissas and weights. Conceptually, the point kernel technique divides an extended source into finite elements and then treats each element as a point source.

MicroShield allows the user to build computer models considering numerous source/shield/exposure point geometries (Fig. 2). The source characteristics required in this application were physical dimensions, chemical composition, and source strength. Shield characteristics included

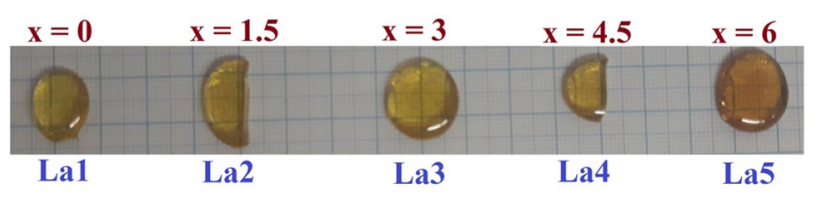

Fig. 1 Glass system image
Table 1 Density, molar volume and calculated optical parameters for the fabricated glasses

\begin{tabular}{|c|c|c|c|c|c|c|c|}
\hline \multirow[t]{2}{*}{ Sample } & \multirow[t]{2}{*}{ Density $\left(\mathrm{g} \mathrm{cm}^{-3}\right)$} & \multirow{2}{*}{$\begin{array}{l}\text { Molar volume } \\
\left(\mathrm{cm}^{3} \mathrm{~mol}^{-1}\right)\end{array}$} & \multicolumn{2}{|c|}{$E_{\mathrm{g}}(\mathrm{eV})$} & \multirow[t]{2}{*}{$E_{\mathrm{o}}(\mathrm{eV})$} & \multirow[t]{2}{*}{$E_{\mathrm{d}}(\mathrm{eV})$} & \multirow[t]{2}{*}{$n_{0}$} \\
\hline & & & Direct & Indirect & & & \\
\hline La1 & 4.2154 & 28.0036 & 2.83 & 2.67 & 2.84 & 3.34 & 2.67 \\
\hline $\mathrm{La} 2$ & 4.4021 & 27.6888 & 2.80 & 2.64 & 2.85 & 5.32 & 2.64 \\
\hline $\mathrm{La} 3$ & 4.6224 & 27.2006 & 2.77 & 2.61 & 2.86 & 8.83 & 2.61 \\
\hline La4 & 5.0241 & 25.7907 & 2.74 & 2.58 & 2.88 & 12.98 & 2.58 \\
\hline La5 & 5.4899 & 24.3024 & 2.71 & 2.55 & 2.91 & 16.33 & 2.55 \\
\hline
\end{tabular}




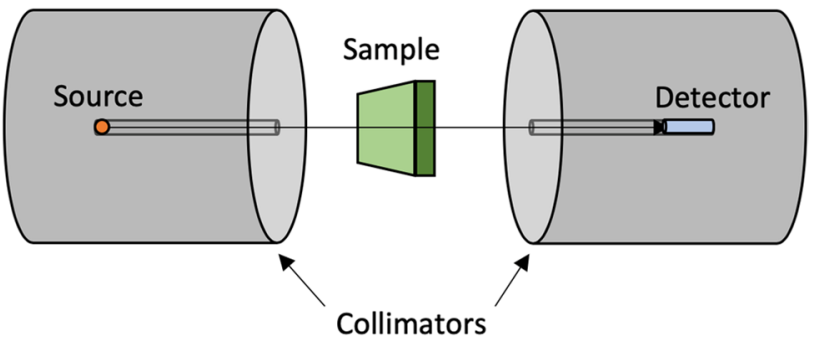

Fig. 2 Sketch of MicroShield simulated geometry for photon attenuation

physical dimensions, chemical composition, and position relative to the source. Custom materials may be generated for the source chemical composition. This information was employed within MicroShield to calculate the photon fluence rate at the point of interest for each photon energy group, both with and without build-up. Library data (radionuclides, attenuation, build-up, and dose conversion) reflect standard data from industry-standard radiation libraries ICRP-38 and ICRP-107 as well as ANSI/ANS Standards and RSICC publications.

In this work, the sample material has been created with Microshield using the density and composition. The mass attenuation coefficient, HVL, MFP, exposure rate with and without build-up factors have been obtained [13].

\section{Results and discussion}

\subsection{X-ray diffraction}

The gradient in the color of the synthesized glass samples with $\mathrm{La}_{2} \mathrm{O}_{3}$ substitution ratio is shown in Fig. 1, and by increasing the $\mathrm{La}_{2} \mathrm{O}_{3}$ substitution ratio, the transparency degree of glass samples was decreased. The diffraction patterns X-ray for $(50-x) \mathrm{B}_{2} \mathrm{O}_{3}-30 \mathrm{PbO}-20 \mathrm{ZnO}-x \mathrm{La}_{2} \mathrm{O}_{3}$, $(x=0,1.5,3,4.5$, and 6$) \mathrm{wt} \%$ synthesized glass with different doping ratio are shown in Fig. 3a. The spectra confirmed the amorphous performance for all samples: the amorphous phase profiles did not show sharp peaks, only humps at around $2 \theta a \sim 28-30$. As a consequence of variations in their short-range structural order, numerous amorphous materials imply individual scattering patterns.

\subsection{Density and molar volume}

Figure $3 \mathrm{~b}$ shows the density and molar volume of the $(50-x) \mathrm{B}_{2} \mathrm{O}_{3}-30 \mathrm{PbO}-20 \mathrm{ZnO}-x \mathrm{La}_{2} \mathrm{O}_{3},(x=0,1.5,3,4.5$, and 6) glass systems at different $\mathrm{La}_{2} \mathrm{O}_{3}$ contents $(x)$. The $\rho$ increased as the $\mathrm{La}_{2} \mathrm{O}_{3}$ substitution ratio of content $(x)$ increased in the glass samples. On the other way, the molar volume decreased with the substitution ratio of content increasing. The addition of $\mathrm{La}_{2} \mathrm{O}_{3}$ oxide causes adjustments in the samples networks through filling the interstitial spaces with $\mathrm{La}_{2} \mathrm{O}_{3}$ which has a higher density and molecular weight $\left(\rho=6.51 \mathrm{~g} / \mathrm{cm}^{3}, \mathrm{M} . \mathrm{W}=325.81 \mathrm{~g} / \mathrm{mol}\right.$, ) than $\mathrm{B}_{2} \mathrm{O}_{3}$ $\left(\rho=2.460 \mathrm{~g} / \mathrm{cm}^{3}\right.$, M.W $\left.=69.62 \mathrm{~g} / \mathrm{mol}\right)$. Furthermore, the molar volume $V_{\mathrm{m}}$ of the glass samples was increased with
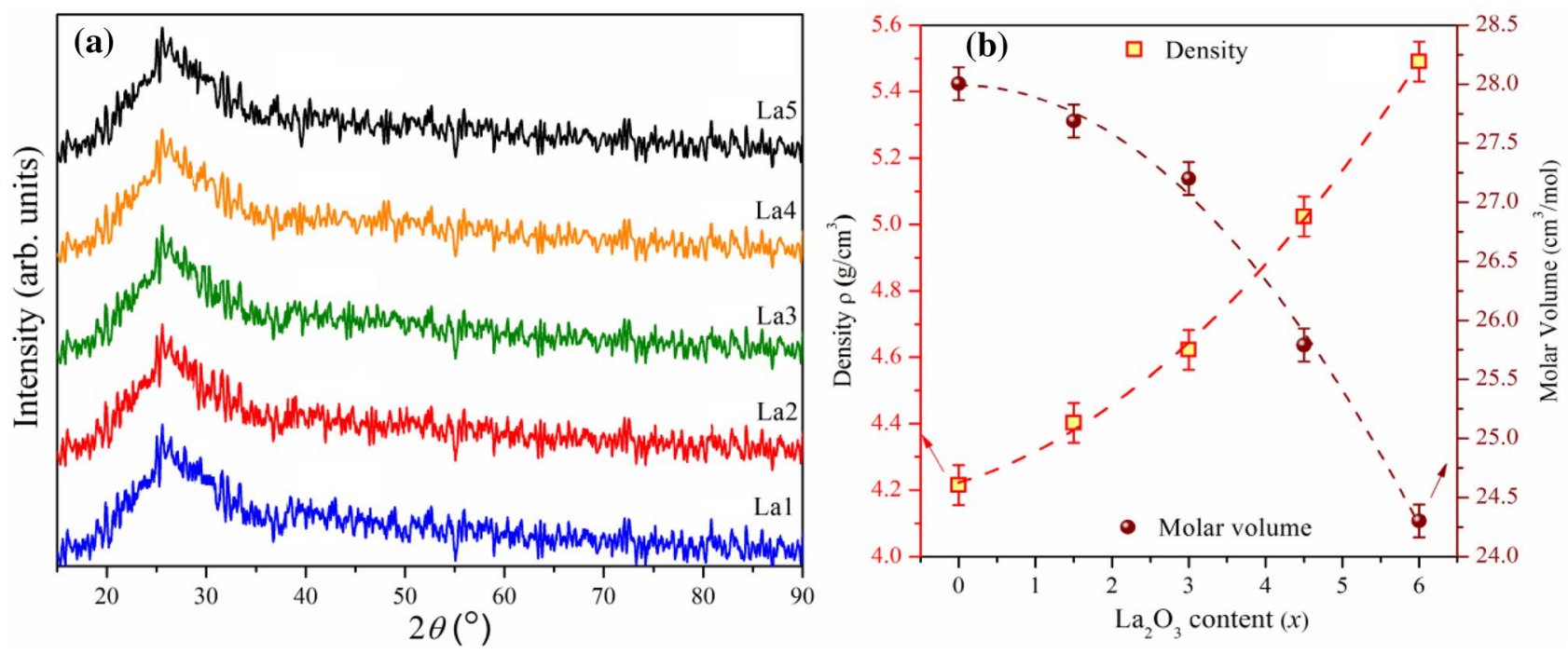

Fig. 3 a X-ray diffraction patterns for the prepared glass samples; b density and molar volume of the glass sample systems as a function of $\mathrm{La}_{2} \mathrm{O}_{3}$ content $(x)$ 
increasing $\mathrm{La}_{2} \mathrm{O}_{3}$ concentration because of the large difference between ionic radius of La (1.032-1.36 ̊) [14] compared to B $(0.11-0.27 \AA)$.

\subsection{Optical properties measurement}

The absorption spectrum in the range of UV-visible of (50 $-x) \mathrm{B}_{2} \mathrm{O}_{3}-30 \mathrm{PbO}-20 \mathrm{ZnO}-x \mathrm{La}_{2} \mathrm{O}_{3},(x=0,1.5,3,4.5$, and 6$)$ glasses is illustrated in Fig. 4a. The increase of $\mathrm{La}_{2} \mathrm{O}_{3}$ content increases the absorbance of synthesized glasses. This increase led to shifting the broad near-visible band focused at about $415 \mathrm{~nm}$ in the direction of a higher wavelength at $430 \mathrm{~nm}$ (redshift), which is produced from the transitions of the bandgap.

The absorption coefficient $\alpha$ was calculated with $\alpha=\frac{2.303 A}{t}$ where $A$ is the absorption and $t$ is the glass samples thickness. It is noticeably that the optical absorption coefficient edges are not sharply realized, which indicates to nature glassy. Moreover, the optical absorption edge was shifted to the higher wavelengths (redshift) with the doping amount of $\mathrm{La}_{2} \mathrm{O}_{3}$ in the glasses is increasing, as seen in Fig. 4b.

The absorption spectrum fitting method (ASF) has been used to assess the optical energy bandgap values for the studied glasses [15, 16]. The model described by Tauc [17]

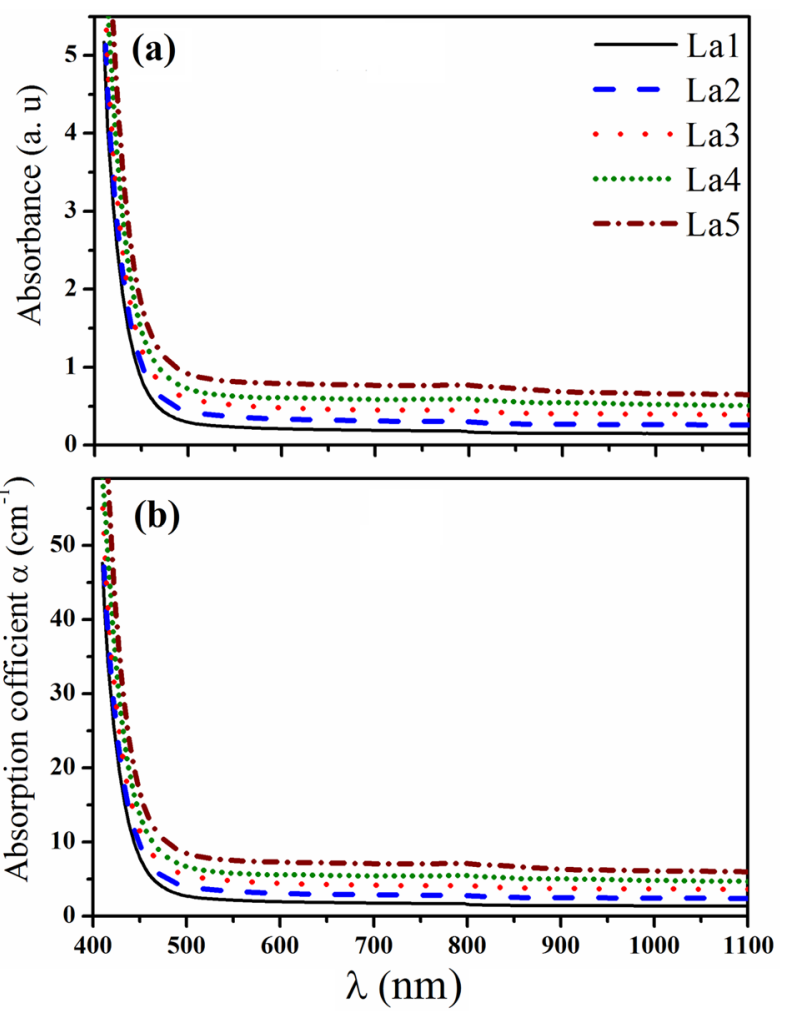

Fig. 4 a UV-visible absorption spectrum of glass samples doped with $\mathrm{La}_{2} \mathrm{O}_{3}$; $\mathbf{b}$ absorption coefficient of glass prepared samples and modified by Davis and Mott [18] can be characterized by Eq. (1):

$\alpha h v=G\left(h v-E^{\text {optical }}\right)^{m}$

where $G$ is a constant, $\left(E^{\text {optical }}\right)$ is the energy of the optical bandgap, and power $(m)$ is the electronic transition: the latter takes two values (namely, 2 and $1 / 2$ ) for the indirect and direct allowed transitions.

The optical absorption coefficient $(\alpha)$ with the wavelength $(\lambda)$ of the incident photon can obtain from the above Eq. 1 as

$\alpha(\lambda)=G(h c)^{m-1} \lambda\left(\frac{1}{\lambda}-\frac{1}{\lambda_{\text {cut }}}\right)^{m}$

$\lambda_{\text {cut }}$ refers to the wavelength cut-off corresponding to the optical bandgap.

The above equation can be modified as follows:

$A(\lambda)=D \lambda\left(\frac{1}{\lambda}-\frac{1}{\lambda_{\text {cut }}}\right)^{m}$

where $D=\left[G(h c)^{m-1} t / 2.303\right]$. Hence, $E^{\text {optical }}$ can be computed directly from $\lambda_{\text {cut }}$ using Eq. (4):

$E_{\mathrm{ASF}}^{\mathrm{optical}}=\frac{h c}{\lambda_{\text {cut }}}=\frac{1239.83}{\lambda_{\text {cut }}}$

The value of $\lambda_{\text {cut }}$ can be obtained through extrapolating the linear region of $(A / \lambda)^{1 / \mathrm{m}}$ against the $\left(\lambda^{-1}\right)$ curve at $(A / \lambda)^{1 / \mathrm{m}}=0$.

Figure $5 \mathrm{a}, \mathrm{b}$ displays the variation of $(A / \lambda)^{2}$ (direct allowed transitions) and $(A / \lambda)^{1 / 2}$ (indirectly allowed transitions) with $(1 / \lambda)$. The direct and indirect $E_{\mathrm{g}}^{\text {optical }}$ values for the investigated samples are decreased with $\mathrm{La}_{2} \mathrm{O}_{3}$ substitution ratio increasing (see Fig. 5). Both indirect and direct transition $E^{\text {optical }}$ values for doped and undoped samples are listed in Table 1. The optical energy of $E_{\mathrm{g}}$ decreased with substitution ratio increasing: this may be due to the difference between the energy gap of $\mathrm{La}_{2} \mathrm{O}_{3}(\sim 5.8 \mathrm{eV})$ [19] and the wide bandgap of $\mathrm{B}_{2} \mathrm{O}_{3}(\sim 6.20 \mathrm{eV})$ [20].

Figure 6 presents the measured UV-visible spectral distribution of the transmittance $T(\lambda)$ and reflectance $R(\lambda)$ for $(50-x) \mathrm{B}_{2} \mathrm{O}_{3}-30 \mathrm{PbO}-20 \mathrm{ZnO}-x \mathrm{La}_{2} \mathrm{O}_{3}$. The results indicate that the transmittance decreases, and the reflectance increases in the visible and the ultra-violet regions for the used glasses materials with the increasing of $\mathrm{La}_{2} \mathrm{O}_{3}$ substitution ratio. Refractive index is calculated using the following known Eq. 5:

$n=\left(\frac{1+R}{1-R}\right)+\left(\frac{4 R}{(1-R)^{2}}-K^{2}\right)^{1 / 2}$

where $R$ is the reflectance, $k$ is the extinction coefficient. Figure 7 interprets the variation of refractive index with the 

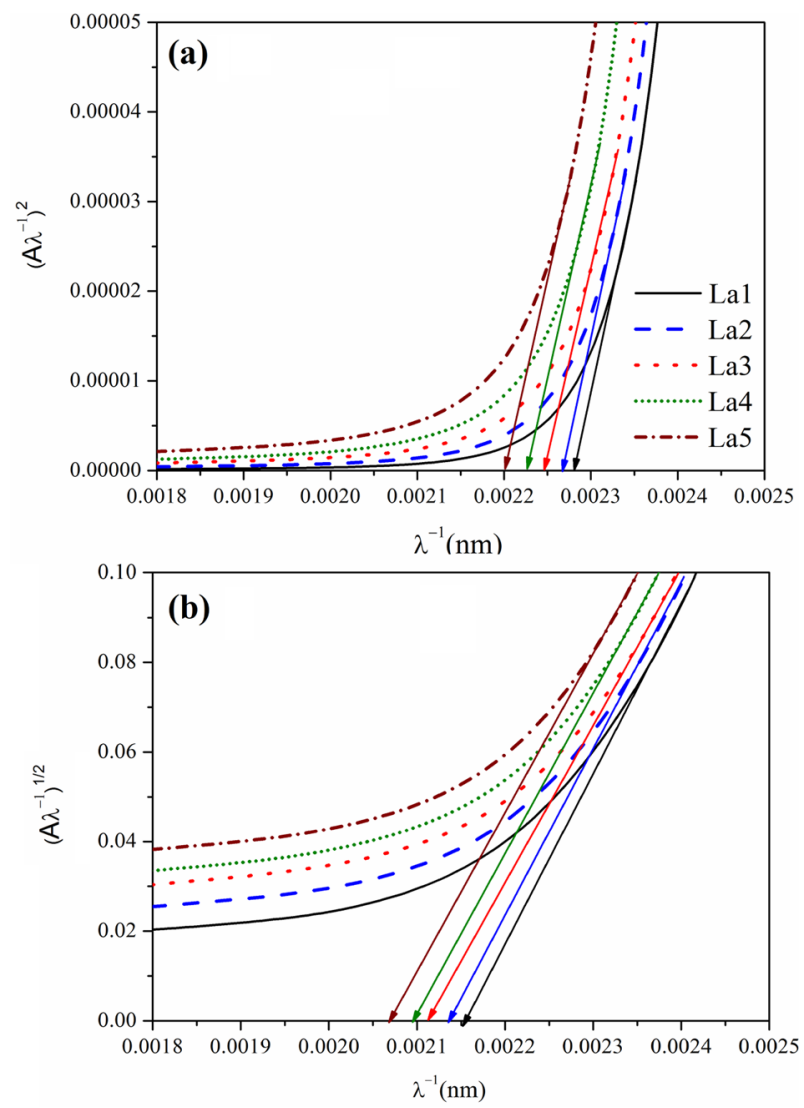

Fig. 5 a, b Variation of $(A / \lambda)^{2}$ and $(A / \lambda)^{1 / 2}$ with $(1 / \lambda)$ for the glass samples

wavelength for the glass samples. The glass samples refractive index increases with increasing the substitution ratio of $\mathrm{a} \mathrm{La}_{2} \mathrm{O}_{3}$. Because the refractive index is considered high, the prepared glass samples can be used to develop the attitude of photovoltaic and optical devices.

The energy distribution parameter of the refractive index $\left(E_{\mathrm{d}}\right)$ and the mean of the single-oscillator energy $\left(E_{\mathrm{o}}\right)$ was estimated utilizing Eq. 6 [20].

$\left(n^{2}-1\right)^{-1}=\frac{E_{0}}{E_{\mathrm{d}}}-\left(\frac{1}{E_{0} E_{\mathrm{d}}}\right)(h v)^{2}$

Figure 8 shows the dependence of $\left(n^{2}-1\right)^{-1}$ on $(h \nu)^{2}$ for the studied samples of glass, the $E_{\mathrm{d}}$ and $E_{\mathrm{o}}$ values are listed in Table 1. It is evident that the increase of the substitution ratio of $\mathrm{La}_{2} \mathrm{O}_{3}$ led to the clear decreasing of single-oscillator energy $\left(E_{\mathrm{o}}\right)$ in the sample of glass, i.e., it has the same as the performance of the $E_{\mathrm{g}}$; however, the dispersion energy parameter $\left(E_{\mathrm{d}}\right)$ has increased.

At zero photon energy, the refractive dispersion index $n_{\mathrm{o}}$ was calculated using the $E_{\mathrm{d}}$ and $E_{\mathrm{o}}$ in Eq. 7 .

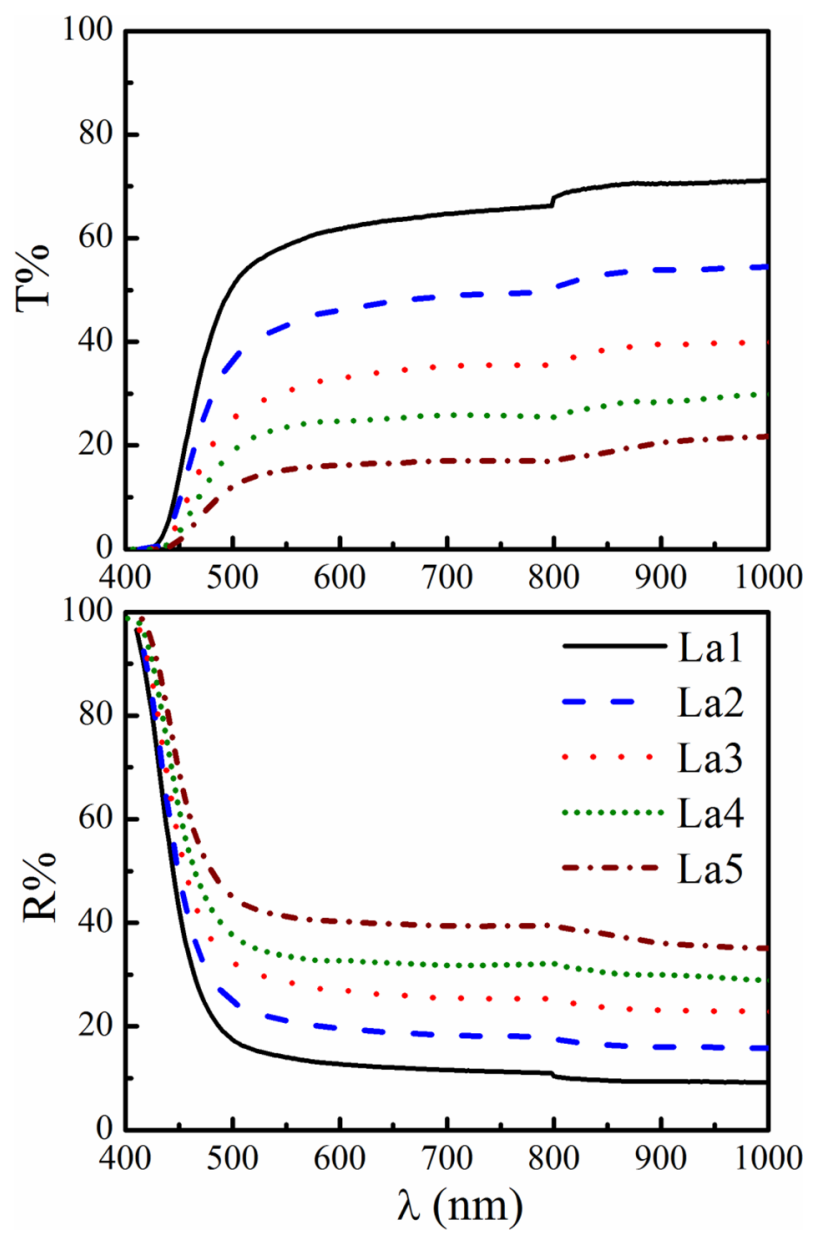

Fig. 6 UV-visible spectral distribution of transmittance $T(\lambda)$ and reflectance $R(\lambda)$ for prepared glass samples

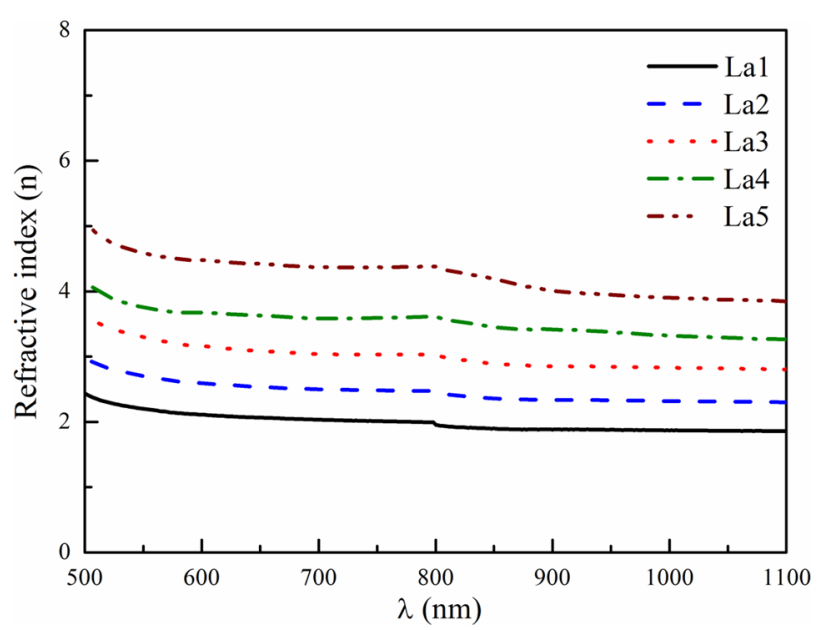

Fig. 7 Dependence of refractive index on wavelength for the glass samples 


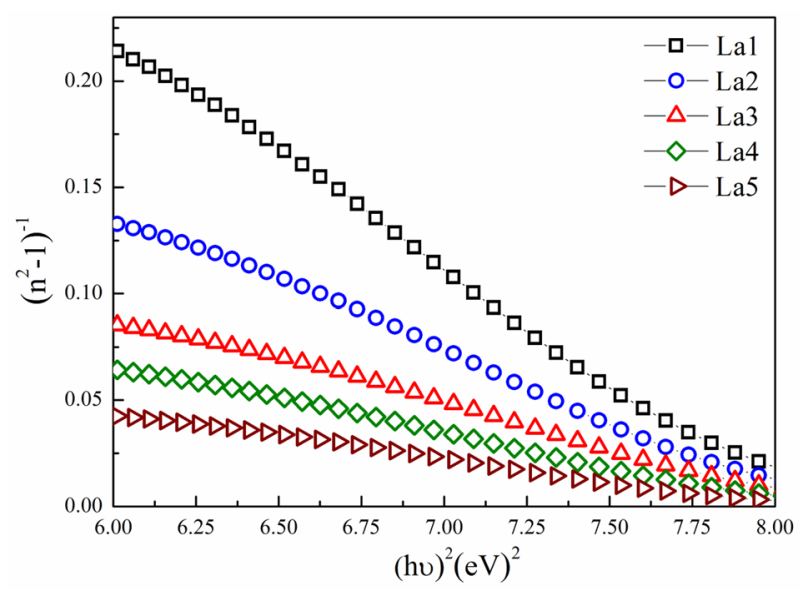

Fig. $8(h \nu)^{2}$ dependence of $\left(n^{2}-1\right)^{-1}$ for all prepared glass samples

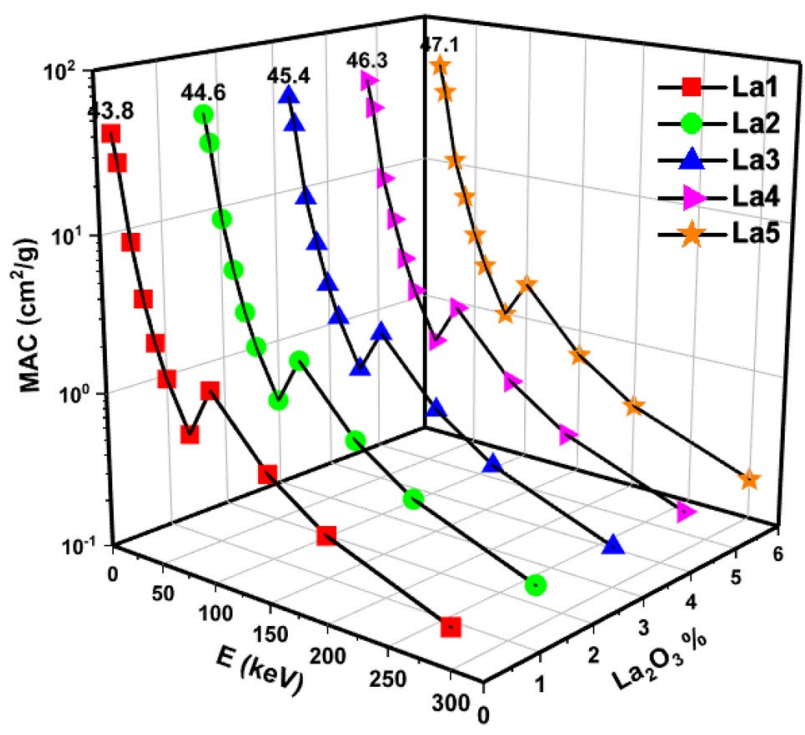

Fig. 9 Mass attenuation coefficient for the five types of glass

$n_{0}^{2}=\left(1+\frac{E_{\mathrm{d}}}{E_{0}}\right)$

The computed $n_{\mathrm{o}}$ for glass samples are presented in Table 1, and they increase with the increasing of $\mathrm{La}_{2} \mathrm{O}_{3}$ substitution ratio.

\subsection{Nuclear radiation shielding behaviors}

The MAC (mass attenuation coefficient) of the different glass samples under study is shown in Fig. 9. As explained in Fig. 9, La5 glass sample demonstrated to have the highest MAC values among the other glass samples under investigation. That is because the addition of La which appeared in the high-density investigated glass. The lowest values

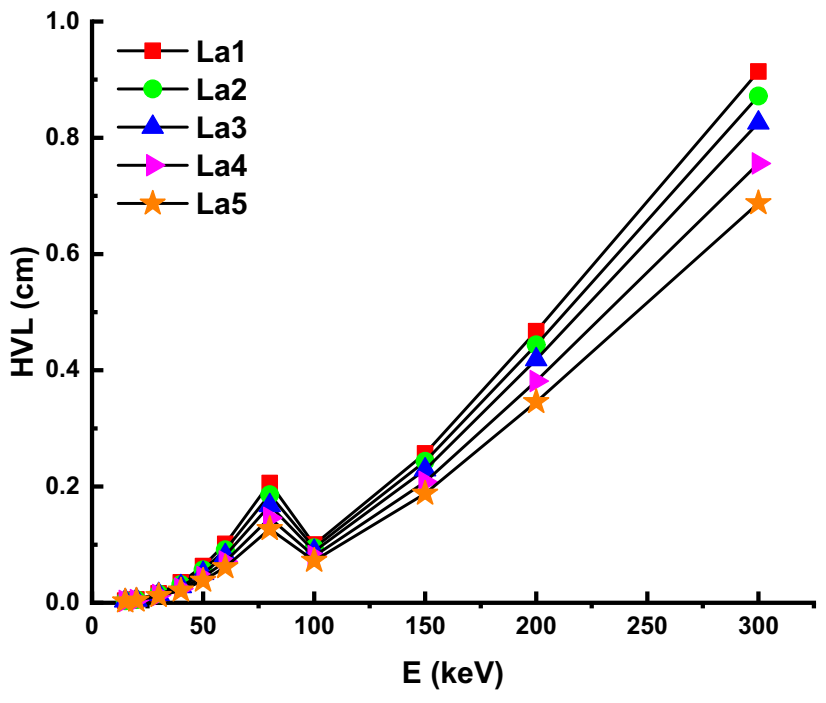

Fig. 10 HVL for five types of glasses in the energy range $15-300 \mathrm{keV}$

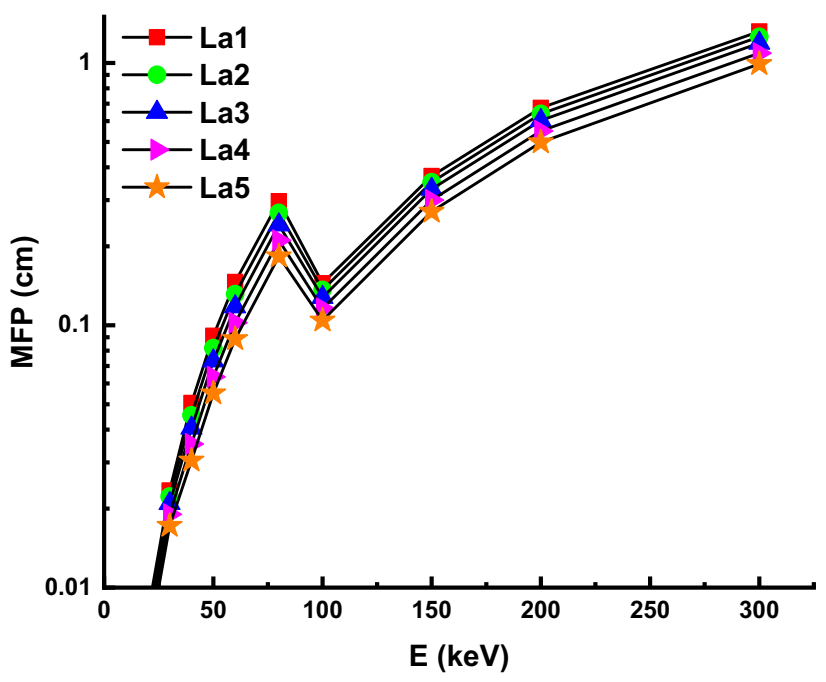

Fig. 11 MFP for five types of glasses in the energy range 15-300 keV

of MAC are for the La1 sample with the lowest density. Besides, the MAC values decrease for all glasses, in the selected energies, as the energy of photon increases with the k-absorption edge of $\mathrm{Pb}$ around $100 \mathrm{keV}$. At low photon energies, the observed quick decrease in MAC values allusions on the photoelectric effect (PEA) $\left(\propto 1 / E^{3.5}\right)$, which dominance over this region [21-23].

The half-value layer (HVL) and the mean free path (MFP) are computed from formulas $\mathrm{HVL}=\ln (2) / \mu$ and MFP $=1 / \mu$, respectively. The lowest HVL and MFP are required for better glass shielding. The HVL and MFP values in the energies of a photon from 15 to $300 \mathrm{keV}$ for the investigated five glass samples are given in Figs. 10 and 11. The results presented in these figures show the variation 
difference of the five glass samples in the photon energy range $15-300 \mathrm{keV}$ with a small peak variance at $75 \mathrm{keV}$. As explained before for MAC behaviors, the HVL and MFP values depend on the incident photon energy corresponding to PEA mechanism dominates at low energy [24]. Results show that, the La1 glass sample requires longer HVL and MFP than the La5 glass sample when energy more than $100-300 \mathrm{keV}$ directly increases. This indicates that the increase in the $\mathrm{La}_{2} \mathrm{O}_{3}$ will decrease the HVL and MFP values with critical point $75 \mathrm{keV}$ (needs more focusing). Moreover, general behavior can be observed from Figs. 10 and 11, that is the HVL and MFP increasing for the studied glass as the photon energy increases. Figure 12 shows the (HVL) as a function of the energy of photon for La5 glass sample (this work), concretes [Ordinary concrete (OC), hematiteserpentine (HSC), ilmenite-limonite (ILC), basalt-magnetite (BMC), ilmenite (IC) and steel-scrap (SSC)] [25] and other glasses (G1 and G2) [26].

Because the radiography $\mathrm{CT}$ room and the hot cells have ranges of $60-120 \mathrm{keV}$ and $90-140 \mathrm{keV}$, respectively, thus, perfect shielding effectiveness of the glass walls or windows in such facilities in the broad energy range of $15-300 \mathrm{keV}$ is essential. The rate exposure without build-up factor against the energy for glass samples is described and presented in Fig. 13. In general, the exposure rate values increase as the photon energy increases in all glass samples. The lowest exposure rate is presented by La5 glass sample at all energies. La5 glass sample considers an excellent performance. On the other hand, La1 glass sample has the highest exposure rate. The exposure rate variation as a function of photon

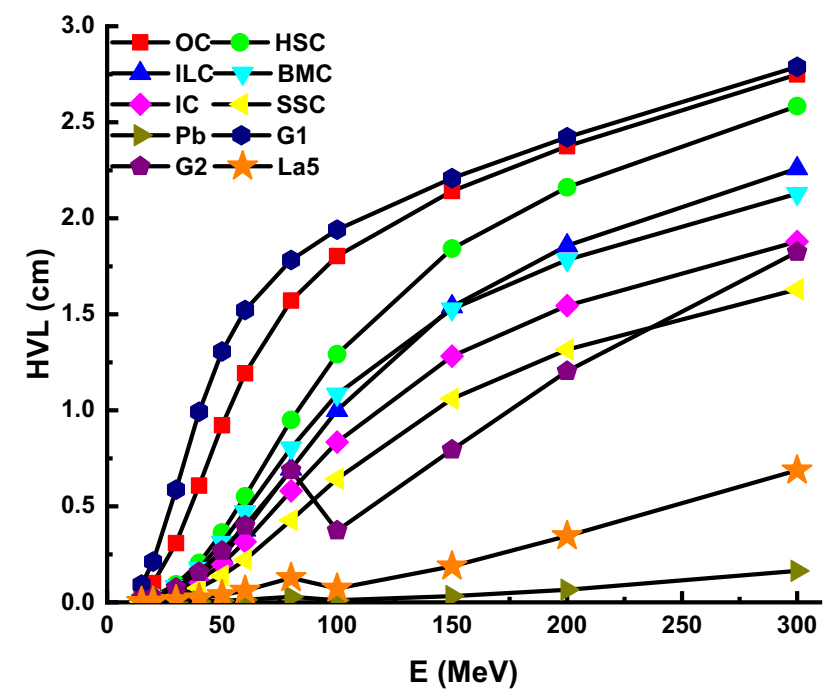

Fig. 12 Half-value layer (HVL) values as a function of photon energy of La5 glass sample (this work), concretes [Ordinary concrete (OC), hematite-serpentine (HSC), ilmenite-limonite (ILC), basalt-magnetite (BMC), ilmenite (IC) and steel-scrap (SSC)] [17] and other glasses (G1 and G2) [18]

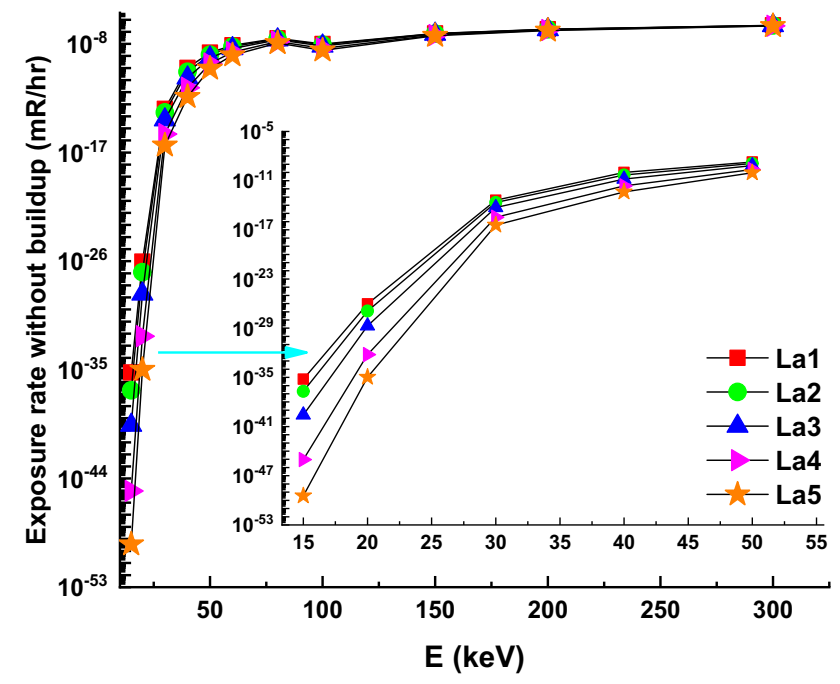

Fig. 13 Exposure rate without build-up factor versus energy for glass samples

energy with and without the build-up factor for the La5 glass sample is described in Fig. 14. As shown in this figure, the exposure rate with build-up factors and without is minimal at low photon energy. This behavior indicates to the calculations of build-up factors which are not necessary for different applications. Figure 15 shows the impact of the La5 sample thickness on the exposure rate. The exposure rate at photon energy more than $200 \mathrm{keV}$ is not affected by the glass thickness. As presented in this figure, the exposure rate increases with the increase in glass sample.

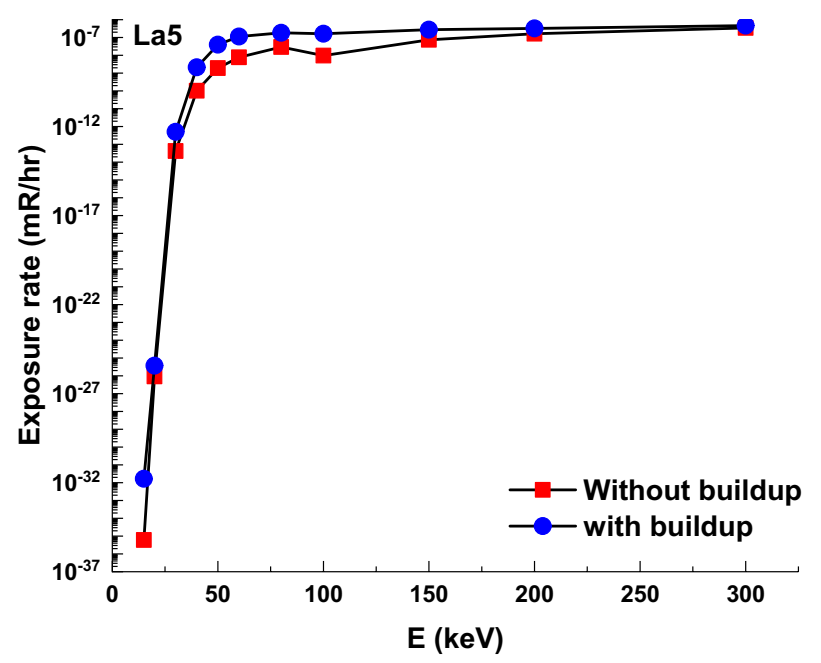

Fig. 14 Variation of exposure rate with and without build-up factor versus energy for La5 glass sample 


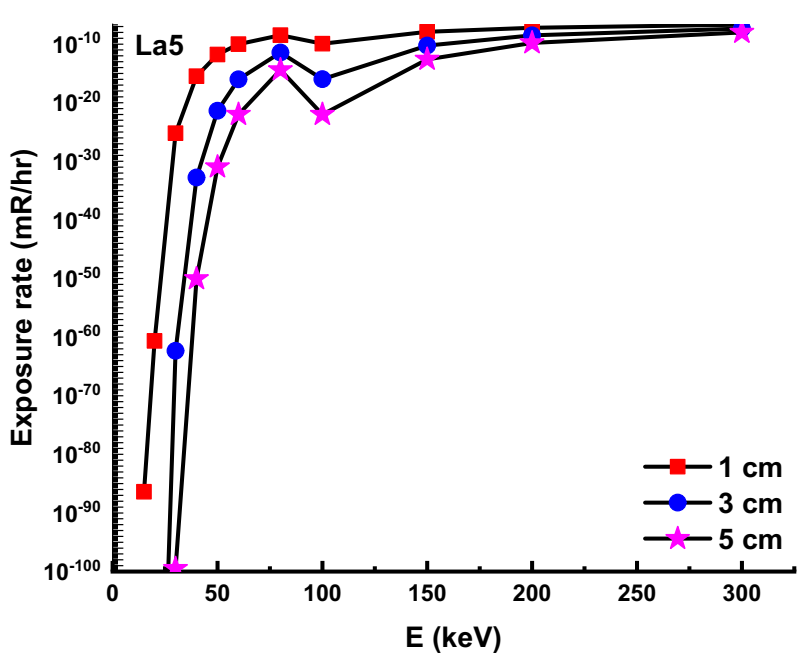

Fig. 15 Dependence of the exposure rate on thickness of La5 glass sample

\section{Conclusion}

In the present study, five samples of lead zinc borate glasses of the composition $(50-x) \mathrm{B}_{2} \mathrm{O}_{3}-30 \mathrm{PbO}-20 \mathrm{ZnO}-x \mathrm{La}_{2} \mathrm{O}_{3} \mathrm{wt} \%$ have been prepared by conventional melt-quenching method with different $\mathrm{La}_{2} \mathrm{O}_{3}$ substitution ratio. XRD measurements confirmed the amorphous nature of all glass samples. The optical energy gap for the examined glasses was decreased in the case of direct transition and indirect transition, while the refractive index was increased with increasing $\mathrm{La}_{2} \mathrm{O}_{3}$ substitution ratio; thus these glass samples can be used to improve the performance of photovoltaic and optical devices. The evaluation of using various types of glass for gamma shielding in the photon energy range $15-300 \mathrm{keV}$ has been done. The results presented that the more additives of lanthanum oxide to the glass improve the radiation shielding properties. The prepared glass sample of $6 \%$ lanthanum oxide $\left(\mathrm{La}_{2} \mathrm{O}_{3}\right)$, $20 \%$ zinc oxide $(\mathrm{ZnO}), 30 \%$ lead oxide $(\mathrm{PbO})$ and $44 \%$ boron oxide $\left(\mathrm{B}_{2} \mathrm{O}_{3}\right)$ named $\mathrm{La} 5$ in this investigation has shown the lowest exposure rate, HVL and MFP values and the best mass MAC, among the other glass samples in the range of energies from 15 to $300 \mathrm{keV}$, which means the La5 glass sample is superior to be used in different applications.

\section{References}

1. H.M. Zakaly, A.S. Abouhaswa, S.A.M. Issa, M.Y.A. Mostafa, M. Pyshkina, R. El-Mallawany, J. Non-Cryst. Solids 543, 120151 (2020)
2. S.A.M. Issa, M.I. Sayyed, M.H.M. Zaid, K.A. Matori, Results Phys. 9, 206 (2018)

3. P. Kaur, D. Singh, T. Singh, Nucl. Eng. Des. 307, 364 (2016)

4. S. Ruengsri, Sci. Technol. Nucl. Install. 2014, 1 (2014)

5. K. Siengsanoh, W. Hongtong, W. Chaiphaksa, P. Limkitjaroenporn, J. Kaewkhao, in J. Phys. Conf. Ser. (Institute of Physics Publishing, 2019).

6. N. Kucuk, Z. Tumsavas, M. Cakir, J. Radiat. Res. 54, 578 (2013)

7. K. Yoshimoto, A. Masuno, M. Ueda, H. Inoue, H. Yamamoto, T. Kawashima, Sci. Rep. 7, 45600 (2017)

8. R. Rajaramakrishna, S. Karuthedath, R.V. Anavekar, H. Jain, J. Non-Cryst. Solids 358, 1667 (2012)

9. K. Yamamoto, H. Kohno, S. Takeda, S. Ichikawa, Appl. Phys. Lett. 89, 083107 (2006)

10. E.-S.A. Waly, G.S. Al-Qous, M.A. Bourham, Radiat. Phys. Chem. 150, 120 (2018)

11. I. S. Mahmoud, S.A.M. Issa, Y.B. Saddeek, H.O. Tekin, O. Kilicoglu, T. Alharbi, M.I. Sayyed, T.T. Erguzel, R. Elsaman, Ceram. Int. (2019)

12. S. Antier, O. Limousin, P. Ferrando, Nucl. Instrum. Methods Phys. Res. Sect. A 787, 297 (2015)

13. M. Rashad, H.O. Tekin, H.M. Zakaly, M. Pyshkina, S.A.M. Issa, G. Susoy, Nucl. Eng. Technol. 52, (2020).

14. R.D. Shannon, Acta Crystallogr. Sect. A 32, 751 (1976)

15. L. Escobar-Alarcón, A. Arrieta, E. Camps, S. Muhl, S. Rodil, E. Vigueras-Santiago, Appl. Surf. Sci. 254, 412 (2007)

16. D. Souri, K. Shomalian, J. Non-Cryst. Solids 355, 1597 (2009)

17. J. Tauc, in Amorphous and Liquid Semiconductors (Springer, New York, 1974), pp. 159-220.

18. N.F. Mott, E.A. Davis, K. Weiser, Phys. Today 25, 55 (1972)

19. G. Shang, P.W. Peacock, J. Robertson, Appl. Phys. Lett. 84, 106 (2004)

20. D. Li, W. Ching, Phys. Rev. B 54, 13616 (1996)

21. S.A.M. Issa, M.I. Sayyed, M. Kurudirek, Bull. Mater. Sci. 40, 841 (2017)

22. S.A.M. Issa, T.A. Hamdalla, A.A.A. Darwish, J. Alloys Compd. 698, 234 (2017)

23. S. Issa, M. Sayyed, M. Kurudirek, J. Phys. Sci. 27, 97 (2016)

24. S.A.M. Issa, A.M.A. Mostafa, T.A. Hanafy, M. Dong, X. Xue, Prog. Nucl. Energy 111, 15 (2019)

25. I.I. Bashter, Ann. Nucl. Energy 24, 1389 (1997)

26. S.A.M. Issa, Y.B. Saddeek, H.O. Tekin, M.I. Sayyed, K. Saber Shaaban, Curr. Appl. Phys. 18, 717 (2018)

Publisher's Note Springer Nature remains neutral with regard to jurisdictional claims in published maps and institutional affiliations. 